\title{
Editorial
}

\section{Revisiting hospitality and tourism: New perspectives}

\author{
Maria D. Alvarez \\ Guest Editor \\ Boğaziçi University (Turkey)
}

Tourism and hospitality are currently facing many challenges as globalization increases the level of competition that organizations operating in this sector are facing. In parallel to this trend, destination management organizations and tourism companies alike have come to realize that it is no longer possible to operate within the same parameters as before. There is an increased awareness and realization that while tourism may be beneficial from an economic perspective as it may increase employment and economic welfare, it may also be detrimental to the environment and the local culture. Therefore, new paradigms and perspectives are emerging. Acknowledging this need for new concepts and theories, scholars worldwide are trying to address the needs of the sector and reinvent the industry.

Destinations are trying to operate within a more challenging and competitive environment, while they are also required to operate within a sustainability perspective. Within this framework, concepts such as poverty alleviation, community-based tourism, stakeholder participation and residents perceptions have permeated scholarly tourism research. However, the implementation of these ideas and practices may not be so straight forward, and there is a need for best practices and practical models that can serve as guidance for destination management organizations.

New developments are also emerging in relation to the composition of the tourists and their needs and motivations. As more senior citizens are participating in the tourism activity, there is a need to understand and address their requirements (Darcy and Buhalis, 2011). Simi- larly, new technological developments are also affecting the way that individuals purchase and consume tourism products.

The special issue Revisiting Hospitality and Tourism: New Perspectives has been designed to address these questions. The papers that have been included were selected among those presented at the First Advances in Hospitality and Tourism Marketing and Management Conference (AHTMM 2011) that was held in Istanbul in June 2011. The conference's main objective was to encourage discussion and creative thought regarding the many challenges that tourism destinations and hospitality organizations are facing. The chosen articles represent a selection that allows the reader to get insights on the many topics discussed during the conference and to give an idea about the spirit of the event.

The first group of papers address destination development and the need for destinations to contribute to poverty alleviation and the welfare of the local community. The first paper by Kimbu focuses on the contribution of tourism to the economic development of the community and the attainment of the Millennium Development Goals. The author proposes a framework to increase the contribution of tourism and discusses its application in the case of Cameroon.

Within the same perspective of sustainable tourism, the article by Ertuna and Kırbaş investigates the participation of the local community in the development of the rural tourism product. The researchers used the organization of an event, a traditional harvest day, to observe the factors that influence the organization and coordination of the local stakeholders in 
creating a rural tourism product.

Building up on the theme of economic and social contribution to the community, Presenza and Iocca investigate these issues in relation to the management of music festivals in Italy. According to these authors, a genuine contribution of these events may only occur within the interaction of the organizer and other public and private stakeholders. Through the use of a stakeholder management approach, the paper analyzes the structure and interaction of stakeholders of music festivals in Italy.

The final paper in the first group is that of Sharma and Dyer, who address the issue of residents' perceptions following a longitudinal approach. The authors compare the attitude of residents in the Australian Gold Coast at two different points in time. They conclude that the perceptions and attitude towards tourism of the residents has become more positive. Furthermore, overall there seems to be a greater level of support for the tourism activity within the community.

The following two papers deal with changes and trends in tourist behaviour. The article by Esichaikul is concerned with the motivations and requirements of European senior tourists travelling to Thailand. With the aim of suggesting policies for the development of the tourism product especially suited to this market, the research determines that these senior tourists are particularly concerned with the safety of the destination, the location of the accommodation and the presence of natural attractions.

Also dealing with consumer behaviour, Harcar and Yucelt's paper focuses on the use of new online technologies as a distribution channel for airline tickets. The research examines the consumers' attitudes towards online transactions for the airline industry. The authors attempt to provide insights regarding the airlines' different distribution channels.

The final group of articles deal with human capital as utilized by the tourism and hospitality industries. García Pozo and his colleagues examine the composition of the Spanish hospitality industry in terms of the degree of specialization and returns on human capital. The study makes a comparison between different regions in Spain, using data from the 2006 Spanish Wage Structure Survey. Differences between regions, as well as conclusions regarding the returns on education are offered by these authors.

Finally, Gökovalı and Avcı examine the role of human capital, as well as collaboration with academia as affecting the degree of innovation of hospitality companies in the Mugla region in Turkey. Using logit and probit econometric models, these authors determine that these factors influence the innovation performance of the hospitality firms.

While these papers offer new insights into the tourism and hospitality industries, they also provide new avenues for future research. Given new theoretical developments resulting from new technologies, changes in the demographic composition of tourists or increased concern for sustainability issues, research is necessary to develop these concepts and to understand new practices. Thus the selection of papers in this special issue may not only contribute to existing conceptual discussions of tourism and hospitality but it may also point towards future avenues for research.

\section{References}

Darcy, S. and Buhalis, D.

2011 "Introduction: From disabled tourists to accessible tourism." In Buhalis, D. and Darcy, S. (Eds.) Accessible Tourism: Concepts and Issues. Bristol, UK: Channel View Publications, 1-20. 